Research Article

\title{
Exploring Ethnic Marginalisation and Indigene-Settler Problems in University Life in Nigeria
}

\author{
E. C. Igbafe $(1)$ \\ Department of Psychology, University of South Africa, Pretoria 0082, South Africa \\ Correspondence should be addressed to E. C. Igbafe; igbafeeucharia@gmail.com
}

Received 3 March 2020; Accepted 2 January 2021; Published 19 January 2021

Academic Editor: Enrique Palou

Copyright (c) 2021 E. C. Igbafe. This is an open access article distributed under the Creative Commons Attribution License, which permits unrestricted use, distribution, and reproduction in any medium, provided the original work is properly cited.

\begin{abstract}
This study investigates ethnic marginalisation and indigene-settler problems at selected universities in Nigeria. Three universities and 12 participants were purposively selected for the study. Face-to-face, semistructured, and individual interviews were utilised to obtain information from the participants regarding their various universities. The data were uploaded on ATLAS.ti 8, qualitative data analysis software for proper management and grouping of transcribed data for further data analysis. Four themes emerged: (a) contextualising ethnic marginalisation and indigene-settler issues; (b) emotional bonds and determination to preserve ancestral land; (c) cultural bonds and determination to preserve traditional practices; and (d) effects of ethnic marginalisation and indigene-settler issues. Further interpretation of the themes revealed that attachment to cultural heritage such as landed properties, cultural life, and practices and economic and indigene dominance were factors driving ethnic marginalisation. The study further found that ethnic marginalisation and indigene-settler problems influenced the emotional and psychological wellbeing and functioning of university lecturers in the selected institutions. The findings also revealed that protests and problems among ethnic groups resulted from the activities of indigenes and settlers when placed in positions of authority (e.g., biased way of recruiting, removing, and promoting ethnic members). The study concludes that there is a need for an integration programme with a practical implementation strategy to ensure peaceful coexistence of ethnic groups within the universities.
\end{abstract}

\section{Introduction}

Meanings and notions of ethnic groups have changed over time, although the concept of ethnic originated from the Latin and Greek words ethnicus and ethnikas, respectively, both meaning nation. Some scholars examined the meaning of ethnic groups and described group members as (a) "people who conceive of themselves as being of a kind. They are united by emotional bonds and concerned with the preservation of their type. With very few exceptions, they speak the same language and they have a common cultural heritage" ([1], p. 47); (b) people who view themselves as "primarily the political community... that inspires the belief in common identity" ([2], p. 38); and (c) a group of people (nation) living together who share and acknowledge common customs [3]. These definitions lead to the concept of ethnic groups having both an objective and a subjective aspect. The objective aspect is having a common name, language, culture, territory, political organisation, and myth of common descent, which foists a common destiny that is essentially behaviour-orientated and dynamic rather than stagnant [1-3]. Osaghae [4] defines the subjective aspect of the definition as having an emotional bond with an ethnic group.

Allan [5] and Ifidon [6] examined different ethnic groups in Nigeria and described them as groups of people linked by lineage, ancestry, historical culture, and the cultural performance of rituals and rights. In these cultural practices, sharing the consciousness of identity with others and acting on its behalf by commanding and displaying love and support for members is promulgated. The Igbo people in eastern Nigeria serve as an example; they are bonded by the Igbo culture that is known as Omenala ndi Igbo and comprises a system of customs, practices, and traditions. The Igbo values are represented in these customs and traditions by visual art, music, and dance forms in addition to attire, 
cuisine, and language dialects [7]. Similar to other ethnic groups in Nigeria, the Igbo people promote and advance these cultural practices, demonstrating their bond and love.

Tajfel et al. [8] examined ethnic groups and identified categorisations such as in-group and out-group. The authors explain that an in-group individual is an individual from an ethnic group who decides to identify emotionally as a member of another ethnic group [8]. They further explain that an out-group individual is an individual who decides not to identify with any ethnic group other than the indigenous group during smaller ethnic group interactions [8]. Some studies argue that these categorisations are characterised by favouritism, a situation where individuals evaluate members positively and associate and allocate resources and other benefits to group members more than to the nongroup members [9]. Some scholars, however, affirm that ethnic categorisations can be a tool for discrimination to promote mediocrity, denying the qualified access to opportunities for employment, well-timed promotion, and placement in a position of authority because of their place of birth and identity [10-12]. Favouring in-groups rather than outgroups is derogatory and a sign of feeling threatened $[13,14]$. Zhang et al. [15] state that the perception of derogation occurs when the views of the in-group are perceived by the out-group as hindering or obstructing the objectives of the in-group. It could be stated that in-group and out-group categorisation and marginalisation may advance indigenesettler problems.

The term "indigenes" describes native dwellers of an area or people with specific rights based on their ancestry or their historical ties to a region and who have a common cultural uniqueness $[16,17]$. Indigenes are commonly referred to as "son[s] of the soil" or "landowners" ([18], p. 9), implying that indigenous people demonstrate three components, ancient bonds (their common roots), lineage (their blood connection), and territory (their geographical location). In Nigeria, the term indigene was created because of the need to guarantee ethnic parity in education and employment opportunities and to preserve traditional ways of life for Nigeria's numerous minority groups [19]. However, the concept has become a powerful means for ethnic exclusion in education, politics, and land ownership because of the increase in poverty and the unemployment level [19].

The term "settlers" refers to "strangers" or "visitors" or "nonindigenes" ([18], p. 9) who have relocated or settled in a region or geographical location that is not their place of origin. Settlers are referred to as nonindigenes and are most often regarded as second-class citizens because they reside outside their ethnic group [19]. Indigene-settler mentality increases the placement of ethnic members as leaders who tend to display intolerance, injustice, and partiality in the distribution of resources and to promote unfair discrimination among the minorities [20].

In this regard, Nwagwu [21] points out that indigenes and settlers are the foundations of the stubborn ethnic problems engulfing Nigeria. Gulati [22] adds that indigenesettler problems are driven by the desire to exclude people who possess certain criteria such as being a member of a different ethnic group. Ehusani [23] asserts that indigenes exploit collaboration and encourage greed and craftiness, allowing the unqualified to gain control of employment instead of the qualified. Kigotho [24] and Nganga [25] identified that current practices in universities employ the ethnic group as a criterion for recruitment, promotion, and appointment regarding positions of power and authority, which undermines the role that human diversity plays in the development of the human capital needs of the nation. Bello [26] supports this finding and affirms that the indigenesettler categorisation promotes mediocrity, overpowers merit, and provides concealment and protection for ethnic colleagues.

Some scholars studied ethnic biases and the differences in dealing with people because of their place of origin, and two major discriminatory activities, namely, personal discrimination displayed in behaviour and institutional discrimination embedded in policies, were identified [27, 28]. Other studies revealed that both personal- and institutionalembedded ethnic discrimination have physical, emotional, and psychological effects [29-32]. These effects sometimes present as unhappiness, somatic criticisms, nervousness, and fixation because of deprivation of quality access to opportunities [33-36]. These identified effects of ethnic discrimination and marginalisation could produce long-lasting pressure [37]; Pascoe and Smart [38, 39]. Overtime, the experience of pressure influences emotions and produces altered behaviours that are adopted as reactions to situations, resulting in additional harm to psychological wellbeing [40].

Consequently, Ikejiani [41] described the effects of ethnic discrimination and marginalisation as a fanatical mental development, an ailment of the mind and a cancer of the body, an antiobjectivity, and an open irrationality towards the practicality of the human fight for development as a country and the type of progress proposed for in a nation. Ikejiani's [41] choice of words indicates that ethnic discrimination and marginalisation could result in an emotional and psychological drain. This occurs if employees' personal beliefs that they are citizens conflict with being judged at work as settlers [15], if ambitions to grow professionally are delayed or thwarted by ethnic marginalisation, and/or if opportunities are only given to indigenes [15], thereby making the settlers feel deprived and viewing their lives as miserable. This emotional and psychological drain could also result from a lack of skills to manage the experienced ethnic marginalisation [42].

Although there is a paucity of research on ethnic marginalisation and indigene-settler issues in university life, available studies indicate that these issues place pressure on individuals and society $[43,44]$. While there is a growing body of research on ethnicity, ethnic marginalisation, and indigenesettler problems, sadly, little is known about the causes, the contexts, the effects, and university management intervention to advance peaceful coexistence in universities. To frame this thinking, I utilised an exploratory interpretative qualitative approach to examine the lived experiences of university lecturers with the aim of suggesting possible interventions to reduce ethnic marginalisation and indigene-settler problems. 


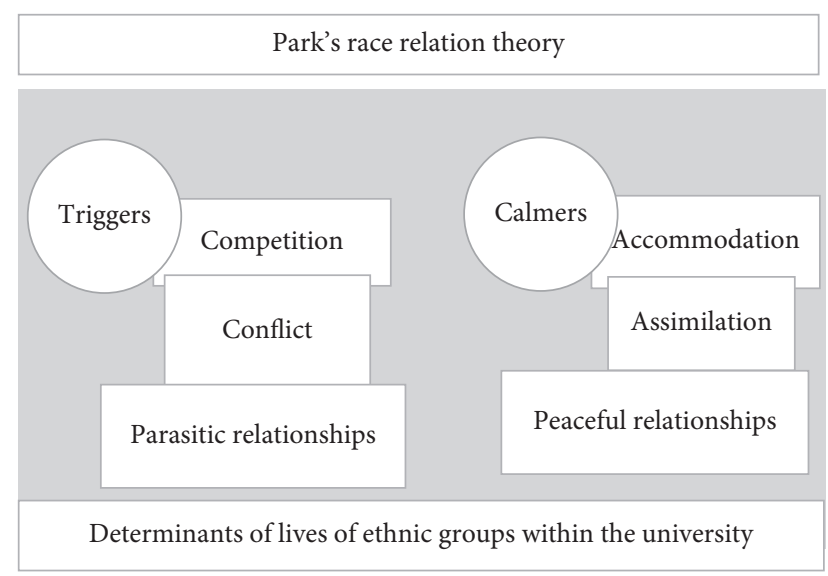

Figure 1: Race relation theory used in the present study. Source: Park [46].

1.1. Theoretical Framework. The race relation theory (RRT) of Park [45] was employed as the theoretical framework for this study and describes the form in which ethnic marginalisation and indigene-settler problems occur in any given social environment. The key principles of the RRT can be grouped into triggers and calmers. The triggers of ethnic marginalisation and indigene-settler issues are competition, conflict, and parasitic relationships, while the calmers are accommodation, assimilation, and peaceful relationships [46].

According to the RRT, competition among ethnic groups for resources, control, and power can lead to ethnic discrimination and marginalisation, which in turn, can result in conflict. The conflict can be observed, unobserved, subtle, or violent, often with the intent to dominate or to eliminate another ethnic group. Ethnic conflicts could be observed if ethnic groups engage in negative competition within the university. Unobserved and subtle conflict could be due to individuals' unconscious fear of the collapse of traditional beliefs and practices [47], which compels them to view practical action such as ethnic marginalisation as essential in dealing with the fear of ethnic domination. Violent and subtle conflict could occur if competition among ethnic groups elicits fear, anxiety, and threat to safety and job security [26]. The conflict could be violent if the pattern of negative competition is characterised by hostility, discrimination, and social interaction that undermines cultural life and practices $[39,48]$. Over time, the negative competition and conflicts produce parasitic relationships in which one ethnic group gains and the others suffer [49]. The RRT maintains that parasitic relationships produce a predictor and prey mentality in which each ethnic group strives to destroy the other. According to Park [46], the predictor-prey mentality furthers competition for higher economic, political, and social status, which finally results in an obvious attack.

According to the RRT, when ethnic groups accommodate each other, they engage in cultural understanding and integration, leading to more positive competition, less conflict, and increased peaceful relationships [46]. Park [46] explains that in assimilation, cultural heritage, expectation, hopes, ideas, opinions, and standards are learnt, mastered, and translated into daily living for survival. Authentic assimilation advances the decision to live together peacefully. Park [45] continues that peaceful relationships develop out of a mutual understanding in terms of similar aims, beliefs, aspirations, and knowledge together with acceptance of each other. Hence, for ethnic groups to continue functioning, peaceful relationships must be created and maintained for reduced parasitic relationships within the university. The theoretical framework comprising triggers and calmers is shown in Figure 1.

\section{Materials and Methods}

2.1. Data and Methods Data. A qualitative, phenomenological research design was adopted in this study to provide the researcher with an opportunity to select appropriate participants with lived experience of the issues under study $[50,51]$. In addition, a phenomenological research design determines the experiences and thoughts of participants, which provides more holistic in-depth information than numerical data $[52,53]$. To obtain in-depth information, a gatekeeper was used to ensure easy access to the research sites [54]. The research sites comprised three selected categories of universities, federal, state, and private and were located in the southeast and south-south geopolitical zones in Nigeria. The criteria for selection of participating universities were as follows: (a) the university must have employees from different ethnic groups; (b) the universities must be established in government-possessed land or individually purchased land; and (c) the universities must have experienced protests or crises relating to ethnic groups or indigene-settler issues. Based on these criteria, a federal government-owned university, a state-owned university with partial funding from the federal government, and a privately owned university with full funding by the owner or owners were sampled for the present study. From these sampled universities, university lecturers from different ethnic groups were selected to participate in the study.

2.2. Participants. The director of research and publication unit for each university was contacted with a written letter that sought approval to engage in the study. Through the heads of department, the directors made an open call to all the employees to indicate interest in participating in the study. Interested employees were given a letter containing an introduction and the objectives of the study to ensure proper understanding before participation. They were also assured of confidentiality. From the university lecturers who indicated interest, the following criteria were used to selected individuals who were best situated for the study: (a) the individual must be an indigene from the community in which the university is established; (b) the individual must be a settler from a different ethnic group; (c) both indigene and settler must have experienced or witnessed ethnic marginalisation or indigene-settler issues sufficiently to produce emotional or psychological strain; and (d) the 
Table 1: Participants sociodemographic background.

\begin{tabular}{|c|c|c|c|c|}
\hline Participant's code name & Age/Gender & Ethnic group (indigene/settler) & Marital status & University type \\
\hline PAIUA & $58 / \mathrm{M}$ & Indigene & Married & Federal \\
\hline PBSUA & $59 / \mathrm{F}$ & Settler & Married & Federal \\
\hline PCIUA & $53 / \mathrm{M}$ & Indigene & Married & Federal \\
\hline PDSUA & $35 / \mathrm{F}$ & Settler & Married & Federal \\
\hline PEIUB & $50 / \mathrm{M}$ & Indigene & Married & State \\
\hline PFSUB & $45 / \mathrm{F}$ & Settler & Married & State \\
\hline PJIUB & $48 / \mathrm{M}$ & Indigene & Married & State \\
\hline PHSUB & $35 / \mathrm{F}$ & Settler & Married & State \\
\hline PIIUC & $50 / \mathrm{M}$ & Indigene & Married & Private \\
\hline PJSUC & $57 / \mathrm{F}$ & Settler & Married & Private \\
\hline PKIUC & $55 / \mathrm{M}$ & Indigene & Married & Private \\
\hline PLSUC & $46 / \mathrm{F}$ & Settler & Married & Private \\
\hline
\end{tabular}

TABle 2: Interview questions and possible probing questions.

\begin{tabular}{|c|c|}
\hline Major question & Possible area of focus \\
\hline 1. Can you introduce yourself? & $\begin{array}{c}\text { Focus on demographic data regarding age/sex, ethnic group, } \\
\text { marital status, and university type }\end{array}$ \\
\hline $\begin{array}{l}\text { 2. Have you experienced ethnic marginalisation and indigene-settler } \\
\text { issues in your university? If yes, elaborate on your experience(s) }\end{array}$ & $\begin{array}{l}\text { Focus on deriving infor } \\
\text { indigene-settler problems, }\end{array}$ \\
\hline $\begin{array}{l}\text { 3. Can you explain the ethnic marginalisation and indigene-settler } \\
\text { issues that you have experienced? }\end{array}$ & $\begin{array}{c}\text { Focus on key identifying experiences of ethnic marginalisation } \\
\text { and indigene-settler issues, if any }\end{array}$ \\
\hline $\begin{array}{l}\text { 4. What are the likely effects of the experienced ethnic marginalisation } \\
\text { and indigene-settler issues within your university? }\end{array}$ & $\begin{array}{c}\text { Determine any possible effects on functional relationships and } \\
\text { productivity }\end{array}$ \\
\hline $\begin{array}{l}\text { 5. How does the university management respond to ethnic } \\
\text { marginalisation and indigene-settler problems? }\end{array}$ & Focus on intervention strategies by university management \\
\hline
\end{tabular}

individual must sign a consent letter to be interviewed and agree to the interviews being audio recorded.

Four participants were selected from each participating university, and thus, a total of 12 participants served as the sample for the study. Purposive sampling was used to ensure the selection of all individuals who met the study criteria [55]. The decision to select 12 participants is based on the principle that a qualitative, phenomenological research design focuses on the use of rich information to determine how and why of the problem under study. To maintain participants' anonymity and confidentiality, pseudonyms were used for participants and their universities. Ethnic groups were identified as follows: indigene university (IU) A or B or C and settler university (SU) A or B or C. Table 1 illustrates participants' sociodemographic backgrounds (age/gender, ethnic group, marital status, and university type) together with their pseudonyms.

It is important to note that all the participants in this study were married; this was not a selection criterion. Divorce and separation were uncommon among the ethnic groups because of cultural norms and standards that uphold marriage.

2.3. Data Collection Procedure. Data were collected face-toface in semistructured interviews using the English language. According to Jamshed [16], semistructured interviews facilitate the gathering of holistic information through engaging and paying close attention to verbal prompts and posing probing questions for deeper insight. Supplementary questions provided an opportunity for a thorough examination of the obtained narratives. The interview questions were approved by the ethical committee of the faculty. Interview schedules were developed and authenticated before administration, and each interview lasted 45-60 mins, depending on the willingness and availability of the participants. Major questions and supplementary questions for the interviews were designed and validated through prior testing in a similar context. Table 2 presents a sample of the major questions and possible supplementary questions.

2.4. Data Analysis. Data were analysed using phenomenological data analysis. To ensure validity, the interviews were recorded and transcribed verbatim. The transcribed data were analysed, and common themes were selected. The themes were developed using Creswell's [56] five steps of analysis: (a) reading and rereading to identify statements that are related to the topics under discussion; (b) separating specific experiences intelligently; (c) grouping the experiences into identical sets; (d) seeking diversity in the experiences; and (f) building themes and subthemes. The data were uploaded on ATLAS.ti 8 to reduce the number of possible errors and to increase the dependability and transparency of the process of examining and interpreting the data [57]. The exact quotations of the participants were used to support and clarify the comments [58]. Comparing and matching the data across the universities was conducted to increase the trustworthiness of the findings as suggested by Bryman [59]. 
2.5. Ethical Considerations. The Ethical Committee of the Faculty of Education, University of Pretoria, provided ethical clearance for the research that produced this manuscript. Ethical clearance code is (EC 12/11/03). This study originated from the researcher's doctoral thesis.

2.6. Findings. This section presents themes resulting from the transcribed data and quotations from the participants' live experiences. The four themes that emerged are as follows: (a) contextualising ethnic marginalisation and indigene-settler issues; (b) emotional bonds and determination to preserve ancestral land; (c) cultural bonds and determination to preserve traditional practices; and (d) effects of ethnic marginalisation and indigene-settler issues.

2.7. Theme1: Contextualising Ethnic Marginalisation and Indigene-Settler Issues. Theme 1 is centred on the context in which ethnic marginalisation occurs and how participants perceived and described the experiences. Recruitment, placement in a position of authority, and promotion were constantly mentioned. Recruitment was the most common strategy for ethnic marginalisation in universities. One participant stated the following comment:

"The ethnic group has become a yardstick for recruitment and promotion of employees in the university. When we relocated to this state because of the crisis in the state, we were, the [name withheld] university was the first place I applied. During the interview, someone came out and said all the indigenes move to this side, pointing to his right and all the non-indigenes move to the other side [left]. The indigenes were interview [sic] one after the other. We, the non-indigenes [settlers], were interview [sic] in groups and after that, we were asked to go. We, the non-indigene[s] exchanged our numbers and emails to keep each other informed about the outcome of the interview. We later found that none of us was employed. It was devastating. Then a friend advised me to apply to this university [meaning the present university], and I got employed. During the promotion, I met all the promotion criteria but when the list came out, I was not promoted. This was not the first [time] I am not promoted because I am not one of them [an indigene]. I was broken psychologically because I worked hard; I deserved to be promoted. At present, I am planning to move to my state where I will not be treated as a non-indigene (PJSUC)."

The above comment of participant PJSUC shows that recruitment and promotion were strategies for ethnic marginalisation and strategies that were faulty and misleading. Faulty because the recruitment process was wrong and promoted open discrimination. Misleading because interviewing indigenes individually and settlers in groups did not dispel the belief regarding the discrimination and marginalisation of settlers within the university. Participant PJSUC used the word "devastating" to describe the hurtful and crippling feeling associated with the betrayal resulting from the university's management attitude towards qualified settlers during recruitment. The process was deemed hurtful because discrimination during recruitment appeared to be a strategy to reduce the number of settlers employed in the university and to be a general design to increase the number of employed indigenes. The promotion process of the university was changed to favour the indigenes, and the settlers who met the promotion criteria were relegated. Participant PJSUC was unprepared for the discrimination that occurred during a promotion in a privately owned university and used the term "broken psychologically" to describe the overwhelming fear of the realities of discrimination based on the ethnic group. The fear that a continued experience of discrimination could thwart personal professional growth may have promoted the decision to relocate to the state of origin. Thus, the decision to relocate to one's state of origin indicates that ethnic marginalisation is shifting the academic migration paradigm, rerouting it towards the individual's indigenous roots, and thus producing a sense of helplessness because of the realisation of the power of in-group to determine the professional progress of the out-group within the university environment.

Another participant reported the years of denied opportunity to change from nonacademic to academic staff as a settler, with indigenes being constantly recruited for the position. The narrative below provides a different perspective of ethnic marginalisation within the university and how ethnic marginalisation leads to relocation to the state of origin:

"When I came to the university to search for employment, they were happy to employ me as a non-academic staff because of my area of specialisation. Then I had a master's degree, trying to complete my $\mathrm{PhD}$ in another university. It was when I completed my PhD and I wanted to change to academic staff that I experienced discrimination. The management told me there was no space for me as academic staff but afterwards, they employed six of their indigenes that graduated three years after me. I felt so bad because I attended several interviews; they kept telling me, "You are good as non-academic staff". It was when a nonindigene became the head of the department that I was accepted as academic staff. That was ten years after. Now I have relocated to my state and I am an indigene (PCIUA)."

Participant PCIUA, an indigene in the current university, reported experienced discrimination in the previous university as a settler. The above comment of this participant revealed that the realities of ethnic marginalisation are more obvious in the context of meeting the human resources needs of the university. Settlers are employed in areas in which indigenes are scarce and are replaced once indigenes are trained to occupy the positions. Discrimination was also reported in the change of work position such as from nonacademic to academic staff, although a settler in a position of leadership subsequently redeemed the situation. Another problem raised in the narrative of participant PCIUA regarding ethnic marginalisation was the impact on emotional quality, which the participant described as "I felt so bad." This participant's decision to relocate suggested the 
painful nature of the experienced discrimination. Thus, the statement "Now I have relocated to my state and I am an indigene" suggests emotional and psychological relief, contentment, and a sense of safety through relocation to the state of origin.

However, some participants explained how some settlers who cannot relocate wait patiently for a settler to assume a position of authority and thereafter promote and recruit settlers:

"The process of employment and promotion or even placement in the position of authority has been used by indigenes and nonindigene [settlers] to dominate each other in the university. Let me explain .... When an indigene is in a leadership position, he/she recruits, promotes and places members of his/her ethnic group in strategic positions. Then, when a nonindigene is in power, she/he recruits promotes and places nonindigenes in positions of authority. So, every time there is a change of leadership, indigenes of the new leader become the authority.... So, this is kind of frustrating ... (PBSUA)."

Participant PBSUA narrated the way in which the quest to recruit, promote, or aid ethnic members in the change from nonacademic to academic positions increased the problems between indigenes and settlers. The need to dominate caused negative competition to become a lifestyle within the university. The extract of participant PBSUA revealed that ethnicity is taking a subtle but dangerous form, which could negatively influence human interaction and the functioning of the university. Subtle, as used here, expressively illustrates the growing conflict and undermines the benefits of human diversity that accrue from employment of experts from different ethnic groups. This dimension of using leadership positions to recruit, place, and promote employees instead of qualification and expertise produces frustration. Participant PBSUA described the situation as "So, this is kind of frustrating," suggesting a tiring trend of intense emotions.

Some participants reported that occupying a leadership position could also be difficult for some settlers at the departmental level. This is demonstrated in the following extract:

\footnotetext{
"When it was my turn to be in a certain leadership position, this very position was occupied according to seniority, but when it was my turn, they changed it and insisted they wanted an indigene. I have also initiated many programmes after accreditation; they will remove me and put an indigene. I felt it is because I am young and a nonindigene. The timing was what made the experiences emotionally tough for me (PHSUB)."
}

The above report of participant PHSUB began with how the refusal to allocate a leadership position according to seniority was another strategy for the ensuing ethnic marginalisation. Participant PHSUB described the way she was denied the right to occupy a position in the department and was constantly removed after initiating new programmes because of her place of birth and identity [10-12]. This participant used the term "emotionally tough" to describe the experienced discrimination as a young settler. The term "emotionally tough" was negatively used to suggest the intensity of the experienced emotions and the difficulties in handling these felt emotions, an indication of the problematic effect of ethnic marginalisation. Participant PHSUB reported that the timing, such as after initiating new programmes, and the refusal for her to occupy a position in the context of ethnic marginalisation had an intense emotional effect on her. Her emphasis on time and context suggested that she felt used, discarded, and targeted as a young settler.

The reason for the intense emotional experience suffered by participant PHSUB was provided by other participants. These participants explained that certain departments of the university adopted a strategy that ensured that every staff member had the opportunity to be in a leadership position at the departmental level. Hence, an individual would experience intense emotion if such an opportunity was denied because of the ethnic group:

"In some departments, the position of authority is turned by turn. But what happens is when it is the turn of a nonindigene to be in authority, some indigenes will never cooperate .... It is unending (PEIUB)."

Participant PEIUB described the strategy adopted in certain departments to eliminate ethnic marginalisation in leadership positions. However, this participant reported the failure of this strategy because of the lack of cooperation of indigenes who preferred an indigene to a settler. The narrative of PEIUB provided insight on the unending nature of the indigene and settler problems in university life, indirectly pinpointing the threats to peaceful relationships and the possibility of future pronounced conflict. In this regard, the following themes explore the possible causes of ethnic discrimination and indigene-settler problems.

2.8. Theme 2: Emotional Bonds and Determination to Preserve Ancestral Land. Theme 2 sought to interpret the reason for indigene and settler domination or marginalisation within the universities. The theme identified how some indigenous people perceived the establishment of the university on the community land owned by families as a problem. The indigenes perceived the establishment of the university on community land as deprivation of the right of indigenous people to preserve cultural ties, heritage, and identity. The participants reported that some of the indigenes perceive marginalisation of people from other ethnic groups as encouraging and as a firm determination to reclaim their rightful position as owners of the land. Some of the participants maintained that ethnic marginalisation in university employment was one of the strategies to curb the influx of settlers into the university. The most significant comment among the reoccurring statements was as follows:

"All the land used in the establishment of this university belongs to the people in this community. It ought to be our 
heritage, but it is lost forever. We cannot farm on it; we cannot sell it to make money. Again, as we are talking now, some of us are worried about the way universities are invading and claiming personal and communities' lands. Where our fathers told us were the boundaries are no longer the boundaries. Most indigenes are not happy. We are left with nothing to live on than to seek jobs in the university (PAIUA)."

The narrative of participant PAIUA shows that the indigenous people have historical, cultural, and spiritual ties in addition to emotional and economic ties to the communal land. The marginalisation of settlers conveys the struggle for ownership, dominance, and power. The statement of participant PAIUA, "It ought to be our heritage, but it is lost forever" disclosed the economic and emotional bonds that indigenes attach to the land. It also highlighted the motive behind indigenes' decisions to discriminate against settlers in order to enjoy communal cultural inheritance [1]. Thus, indigenes form a political group to increase the power to dominate [2] other ethnic groups. Through their behaviour, indigenes also display the emotional bonds with their ethnic group and ancestral heritage [1, 3, 4]. Participant PAIUA adds that another reason for ethnic marginalisation is to build economic power and indicated that economic power can be attained from other businesses; many indigenes engage in small-scale farming to improve their standard of living. The statement "Where our fathers told us were the boundaries are no longer the boundaries" (participant PAIUA) highlights the power of oral history and the important role it plays in the preservation of cultural heritage.

Some participants reported that indigene and settler problems were common across the universities, and that land ownership has been implicated as the reoccurring reason. One participant reported the commonness of this idea in many universities:

"It is common in all institutions in this country; the indigenes of the location would always claim their ancestral land [s] were taken. So, the compensation is to employ more indigenes at the expense of qualified nonindigenes. Yes! We all see the land [on which] the universities were established as a lost inheritance. Therefore, private universities are different; they buy the land from their owners or communities, so people do not feel they were deprived of their ancestral land. It is sad. These land issues have also introduced distrust among ethnic groups in the university system (PEIUB)."

Participant PEIUB reported that many universities are involved in the marginalisation of other ethnic groups to favour their indigenes. Some universities even undermine qualified and experienced nonindigenes to employ less qualified indigenes. The narration of participant PEIUB shows that ancestral inheritance has a completely different meaning among indigenous people. The quest to preserve community-owned land, the source of the mutual bond among indigenes, permeated the universities. Participant PEIUB illustrated that the emotional bond with ancestral land is valued more than the promotion of diversity through employment of settlers. This participant further illustrated that indigenes' emotional bonds have historical, cultural, and spiritual attachments, in which the employment of settlers negatively provoked. Furthermore, the above quotation shows that community land is a link between indigenes and their ancestors through the performance of cultural rituals and rights on the land [5-7]. The account of participant PEIUB also demonstrated that indigenes' knowledge of cultural practices and their reverence to the land as their ancestral heritage have survived modernisation. The statement " $\mathrm{I}] \mathrm{t}$ is common in all the institutions in this country" emphasises the rising quest of indigenes to claim ownership and the seriousness of the problem. It is an indication that the establishment of a university on community land without understanding the cultural meaning of the land to the people could provoke a reaction in the future.

One participant linked the cause of ethnic marginalisation to the quest for resource control, which is elucidated in the following comment:

"I think the problem is not mainly about land. I think it is about resource control for economic and political domination in decision-making and other affairs of the university (PLSUC)."

By tradition, the land determines who are kindred (ingroup) and who are not (out-group) [8,18]. For indigenes, the land provides financial power, which is the most important exponent of political domination. The report of participant PLSUC tried to portray the indigenes' power to dominate the affairs of the university from a settler's perspective. Land, economic, and political power and the power to decide are intertwined. The owners of the land are important to the university, and hence, one of the goals of educational institutions is community engagement. Through community engagement, the university collaborates with indigenes to identify, analyse, and solve problems. This strategy promotes a sense of ownership and a sustainable relationship regarding the development of the community, providing a common outline aimed at building consistent dialogic relationships between the indigenes and other university members. However, when indigenes feel their right of ownership is neglected, the result is resentment of other ethnic groups. This is the case in the next theme in which indigenes felt that their cultural rituals and practices were disrespected.

\subsection{Theme 3: Cultural Bonds and Determination to Preserve} Traditional Practices. Theme 3 presents cultural bonds and determination to revitalise, preserve, and protect the traditional practices as reasons for the ethnic marginalisation of settlers. Traditional practices embedded in cultural rituals and observances contribute to the identity of the indigenes in the university. Cultural ceremonial observances considered the essence of the connection to the ancestors and the spirit for the protection of the lineage from extinction. Furthermore, respecting and protecting cultural practice is 
the source of existence and ethnic continuity. Some of the participants described their cultural bonds and their intense desire to restore and preserve the practices as reasons for the increase in ethnic marginalisation in most universities. These participants believe that their cultural practices will be restored and preserved if nonindigenes who detest their traditional heritage are eliminated from the university. Some of the participants mentioned disrespect for cultural life and practices as a cause of indigene-settler issues within the university. Disrespect was viewed as the constant demonising of many cultural activities and the designation of them as fetishes. Indigenes fear the loss of identity and thus need to revive, promote, and sustain cultural heritage, as is demonstrated in the following comment:

"As a university lecturer, people think I cannot practise my traditional religion. I cannot go to the shrine and worship my ancestors. I cannot make sacrifices and pour libation to my ancestors because I obtained [a] Western education. When I do, I am demonised and called [a] fetish. Some of these non-indigenes can criticise our cultural life and practices, even our best practices. We indigenes who are traditionalist are openly discriminated against and condemned. Some of the indigenes have joined in demonising our cultural practices. Our ways of greeting, dressing, dancing, birth and burial rites, as well as marriage rites, are demonised and changed. Some of us hardly know who we are. We want an opportunity to proudly practice our cultural heritage; it is who we are. We welcome non-indigenes who love our cultural values. We can only promote our culture by giving our people who are aware of the dangers of losing our identity opportunity at the university (PAIUA)."

The comment of participant PAIUA emphasises the importance that the indigenes who participated in this study attach to their traditional practices. For participant PAIUA, traditional practices form a way of life, and indigenes should not be shamed within the university system. The above account has an emotional undertone, portraying the strong cultural bond with traditional religion and the desire to engage openly in religious practices within the university. Participant PAIUA displayed a fanatical attitude towards traditional ideologies, which is clear in the comment "We want an opportunity to proudly practice our cultural heritage; it is who we are." Such fanaticism could result in the marginalisation of settlers who view the traditional practice as a fetish. This participant's capacity to promote traditional religion and the practices as a way of life was further emphasised in the comment "We welcome nonindigenes who love our cultural values," suggesting that settlers who love indigenous practices should be employed. The fanatical cultural bond of participant PAIUA could provoke ethnic marginalisation and initiate contest for power at any time.

Other participants also displayed the fanaticism of participant PAIUA for cultural life and practices. Prominent among the participants are those who viewed disrespect of cultural practice as provocative and as the origin of the hatred for certain ethnic groups:
"Our cultural life and practices are dying out. Our sacred land[s] are violated and sold without full consultation. Some of these non-indigenes because they have money, they convince the poor villagers to sell the community sacred land to them. These sacred lands are the root of our spiritual [bonds] to our ancestors because we perform our rituals and makes [sic] sacrifices in these lands. Establishing university or religious organisation in these lands do benefit us. However, it did us more harm by disconnecting us from our ancestors; it demotivates our people from upholding our cultural practices. Again, this is provocative when the non-indigenes employed in the university [are] undermining our people's cultural life. It leads to hatred towards anyone from such ethnic group [s]. To protect our culture, most of us can do anything (PGIUB)."

Participant PGIUB presented the image of culture as the essence of the life of indigenes. Thus, every activity that violates the upholding of cultural practice is considered insubordination, and the ethnic group that conducts such activities is marginalised. Participant PGIUB provided an example of cultural violation, the selling of sacred land. The sacred land represents the indigene's symbol of unity and spiritual connection to the ancestors through worship, libation, and sacrifices. The sacred land is also the seat of governance for kindred and is a reminder of ancestral conquest and survival histories, the sacred animals, and trees. Hence, tampering with sacred land by other ethnic groups is provocative and could lead to discrimination against such groups. Participant PGIUB justified discrimination by saying "To protect our culture, most of us [indigenes] can do anything," thereby emphasising marginalisation as a strategy for cultural protection and preservation. The report of this participant revealed an emotional bond to cultural life and practices, highlighting the need for protection by using ethnic marginalisation. This implies that a lecturer's life outside the university environment influences and determines how the individual is perceived and treated within the institution.

Another participant affirmed that the need to protect the culture promotes the intention to marginalise:

"Some of us are no longer confrontable with demonising our cultural practices. Most lecturers cannot connect with our cultural practices because they do not know the historical background and do know not what to know. This is obvious in some universities; you will see the Church and mosque, [but] have you seen a shrine for traditionalist [s]? It is sad; colleagues think all traditional practices are bad. Some of us need to hide our love for our culture to retain my [sic] job. This is very unfair (PLSUC)."

Participant PLSUC used the vocabulary "no longer comfortable" to describe indigene's unwillingness to accommodate settlers who cannot understand, value, and respect their cultural life and practices. The words revealed a sense of discomfort with cultural violations such as outright rejection, ridicule, and abuse of traditional religion. According to participant PLSUC, in his university, "Most 
lecturers cannot connect with our cultural practices because they do not know the historical background and do know not what to know." Emphasising some lecturers' reluctance to accommodate the indigenes' cultural rights and rituals, participant PLSUC indicated the lack of cultural assimilation within the university environment and provided evidence in the statement "This is obvious in some universities; you will see the church and mosque, [but] have you seen a shrine for traditionalist[s]?" The participant described a setting that excludes the cultural life and practices of indigenes but accommodates other ideologies, thereby making certain members of the university view indigenous practices as bad. Participant PLSUC acknowledged that bad cultural practices exist, but at the same time, explained that there are good cultural practices. The demonstration of the emotional bond to culture in the above quotation highlighted the sad realisation of the increasing inability to reveal oneself as a traditional worshiper in a university environment. Participant PLSUC described the present state within the university regarding practising traditional beliefs as follows: "Some of us need to hide our love for our culture to retain my job." In comparison with the freedom given to worshippers of other religions, the participant's emotions and sense of helplessness are displayed in the statement "This is very unfair," depicting a state that can trigger hate, resentment, and discrimination towards settlers who demonise the cultural life and practices $[39,48]$ of the indigenes. The emphasis on culture draws attention to the reawakening of the indigenous people who are striving to assert themselves and reclaim their cultural life and practices notwithstanding the environment. Participant PLSUC provided a deeper understanding of why settlers could be marginalised in the universities.

2.10. Theme 4: Effects of Ethnic Marginalisation and IndigeneSettler Issues. Some participants reported the effects of ethnic marginalisation. Experiencing ethnic discrimination, marginalisation, and indigene-settler issues has effects on both indigenes and settlers. Constantly mentioned were the emotional, physical, and psychological effects that shaped participants' interpersonal relationships and work attitudes. One participant mentioned that experiencing ethnic discrimination destroyed the zeal to socialise within the university:

"The zeal to work or socialise with people die. The desire to sharing my experiences and knowledge was killed by discrimination. I started minding my business and ignored them [indigenes]. In departmental meetings or any committee, all I do is to say yes or no. I do not relate. Simply, I started isolating myself from most professional activities that would involve socialising with some colleagues that support the marginalisation of non-indigenes. I did these to protect myself from the emotional and psychological pains of being called an outsider in my own country. There were times I never felt like going to work. I was depressed, felt sad. A colleague friend drew my attention to the fact that I am becoming aggressive and hostile. It was when I could not cope again that I relocated to $m y$ state of origin and got a job in this university (PCIUA)."

Participant PCIUA described the effects of experienced discrimination to include emotional, physical, psychological, and social strain. According to this participant, the original excitement and commitment to work were reduced to the barest minimum, leading to the desire to avoid work. Participant PCIUA explained that the desire to engage in social interactions and knowledge-sharing with colleagues figuratively died. He became sad, depressed, aggressive, and hostile towards colleagues. He further explained that his emotional and psychological issues were due to being perceived as a settler in his own country. Another participant described being referred to as a settler affected work behaviour:

"The feeling of someone calling me a settler in my own
country affected my self-esteem and lowered my motivation
to put in my best. My passion to work hard stopped.
Honestly, I changed from committed to uncommitted,
productive to unproductive, approachable to unap-
proachable, happy worker to withdrawn to deal with the
experienced discriminatory attitudes. I said to myself, "[T]
here is no need to work hard; when it comes to promotion or
placement in a leadership position, they will not consider
my hard work" (PHSUB)."

Participant PHSUB, a junior lecturer and a settler, described the way that discrimination because of place of birth negatively changed her ideology concerning her work behaviour and affected how she valued herself. Her description of experienced discrimination revealed an emotional tone of pain, hurt, and helplessness. Over time, the experience of such discrimination could affect wellbeing, professional progress, and quality of productivity at the university. Some of the participants sampled as indigenes shared their experience as nonindigenes in their previous universities:

"The effects of been called a nonindigene in my country
were not pleasant. It changed my feelings once I drove into
the university environment. It is like I could feel my veins
cracking with anxiety... I was discriminated against when
we had a project to execute. Though they knew it was my
area of specialisation, they, the indigenes, collaborate to do
the work. I got tired of the hostility. I relocated to this
university; now I am an indigene. I understand the ex-
perience of someone who feels marginalised; it is not a good
thing emotionally (PFSUB)."

Participant PFSUB, previously a settler and now an indigene, reported the physical and emotional effects of being marginalised because of the ethnic group. The narration of this participant indicates the traumatic effect of experienced discrimination and the inability to cope, leading to relocation to the state of origin. The emotional tone of participant PFSUB also suggests a feeling of being used and a feeling of helplessness. Another indigene described the effects of ethnic discrimination as follows: 
"I came to my previous university as a nonindigene. I initiated many programmes; however, I observed that once the project takes off, I would be replaced immediately by an indigene. At first, I thought it was a coincidence until it happened more than three times. I was disheartened; I felt miserable until I relocated to this university in my community (PJIUB).”

The experience of discrimination by participant PJIUB resulted in the loss of self-confidence and the loss of hope to grow professionally in the former university as a settler, thus relocation to the state of origin. A thorough examination of the named emotions of participant PJIUB such as disheartenment and misery revealed that ethnic marginalisation influences the individual, impacts on work behaviour, and subsequently influences the decision to relocate to another university.

\section{Discussion}

This study sought to understand indigene-settler problems in university life in selected Nigerian universities. A qualitative design of interpretative phenomenological analysis was used to examine ethnic marginalisation and indigenesettler issues. Four significant findings resulted from the analysis of data and theme discussion.

The first was the diverse reasons for ethnic marginalisation and indigene-settler problems. The land occupied by the university was viewed as an instrument for sustainable generational wealth. The occupancy of the land by the university meant deprivation of economic power and sources of food. This is in line with Muzan [60] who states that land use and proprietary rights activate ethnic problems. Hence, some indigenes maintained that it is their right to control the affairs of the university. This finding is in line with Lonsdale [61] who states that the ethnic group is an administrative weapon for economic empowerment of ethnic members, creating a system of employment and placement in positions of authority for continuous economic, position, and power domination. Notably, this finding confirms the assumption that indigenes are consciously and unconsciously attached to the land as a traditional heritage and believed parental stories on land ownership and acquisition. Hence, indigenes work hard to remain connected to their land and, in so doing, engage in ethnic marginalisation to achieve their goal of obtaining economic gains through the ancestral lands that the university occupies.

In addition, the finding of the revival of cultural life and practices as a reason for indigene-settler issues revealed the emotional bond with cultural heritage, indicating that some participants are psychologically, physically, and socially attached to their cultural roots. These participants consider shaming and insulting their cultural rituals and rites abhorrent. This finding is interesting because it highlights that despite the populations of other religions in Nigeria, individuals yearn to promote their traditional religion. This need promotes cultural practices, which is evident in the statement, "[Y]ou will see the church and mosque in the universities, [but] have you seen a shrine for traditionalist [s]?" This agrees with the assertion of Sherif [39] who argues that the need to protect the cultural life of the people could trigger indigene-settler problems. In general, these findings on reasons for indigene-settler issues revealed that many participants are attached to their cultural heritage be it landed property or cultural practices.

The second finding was from the context of the ethnic marginalisation and indigene-settler problems. Ethnic discrimination was found during recruitment, promotion, and placement in a position of authority. Through this discrimination, some participants experienced emotional and psychological drain, making them feel miserable about their work-life. This aligns with Zhang [15] who assert that deprivation of opportunities promotes feelings of misery in life, while the lack of skills to handle the pressure associated with these feelings intensifies the experienced pressure [42]. The context of indigene-settler issues and the timing played an important role in determining the type of experience for the participants.

The third finding on the effects of experienced ethnic marginalisation and indigene-settler problems presented as negative interpersonal relationships and work attitude. The effects of indigene-settler issues were found to be psychological because of the perception of the experience as thwarting, depriving, and judgemental of participants' cultural life and practices, labelling them demonic and a fetish. This finding is in line with studies that report that psychological draining could occur if there is competing and conflicting beliefs that thwart or delay opportunities to achieve the desired goal [15]. Some of the participants sought to change their experienced negative emotions to deal with the parasitism found in relationships among ethnic groups [49]. This aligns with Diesendruck et al. [62] who assert that negative emotions in the ethnicist's environment could increase suspicion and hatred towards the indigenes. This seems to agree with the work of Park [45] who maintains that if competition and conflict characterise a system, true accommodation and assimilation between indigenes and settlers will be disrupted because there was never a true interaction and relationship. This present finding is further supported by Alubo [63] who states that ordering and the feeling of being ordered among ethnic groups breed indigene-settler problems, thus furthering the categorisation of employees' relationships into an in-group, out-group, or neutral group [8].

To deal with the effects of the experienced emotions, many of the participants engaged in self-withdrawal, emotional suppression, and situation acceptance. Some of the participants mentioned that they engaged in self-withdrawal that entailed avoidance of formal and informal interactions with their ethnicist colleagues except in unavoidable official roles. Participants achieved self-withdrawal through passivity to issues raised at the faculty or departmental level. Self-withdrawal was identified as a common approach for addressing issues among indigenes and settlers. This finding supports studies that linked ingroup and out-group with self-withdrawal as a strategy for addressing ethnic issues $[64,65]$. Some participants 
mentioned that they engaged in emotional suppression such as refusal to express identified and labelled emotions, which led to struggling to keep calm $[66,67]$ during or after the experienced ethnic marginalisation. This aligns with other studies that report that emotional suppression leads to increased emotional distress and nervousness $[68,69]$. In addition, many of the participants engaged in situation acceptance and hence never made an effort to report to the university management officially. Situation acceptance was expected since most of the participants blamed university management for the poor response to ethnic marginalisation. Situation acceptance could affect the participants and heighten nonreactivity because of the willingness to go through the emotional impact of a situation [70].

The findings of this present study demonstrate that ethnic marginalisation and indigene-settler problems are the consequences of inadequate peaceful relationships (accommodation and assimilation) among ethnic groups [46]. Participants' comments indicated competition for resource control and economic power, which heightened the negative perceptions of one another among ethnic groups. Finally, it is appalling that university management has not received an official report on ethnic marginalisation and indigene-settler problems. It is hoped that relevant services would be provided if university management receives reports regarding these issues. When confronted with the protests that repeatedly occur when a settler is placed in a position of authority, rather than feigning ignorance, provision of such services would help integrate ethnic groups within the system for a more peaceful coexistence. A central problem identified in this study is determining which strategies and practical implementation processes are more likely to encourage and support integration to ensure peaceful coexistence. Without official reports from university lecturers, investigations into ethnic marginalisation and indigenesettler issues may not be effective. University lecturers are in danger of emotional and psychological breakdown; there is the need for intervention of university management (facultydepartment) and ethnic groups.

3.1. Finding Implications. The findings of the present study have the following practical implications. First, university management and the government should consider implementing a strategy for employment of indigenes and settlers that does not undermine diversity. To achieve this, both academic and nonacademic institutions should be restructured to reflect ethnic diversity [71]. Second, the easiest way to achieve ethnic integration is by initiating a practical programme to promote authentic accommodation, assimilation, and peaceful relationships [46]. Third, the findings revealed a connection between intentions to promote and preserve indigenous cultural heritage and indigene-settler problems, which indicated the contribution of cultural and emotional bonds to increasing ethnic marginalisations within the universities. As institutions of higher learning, there is a need for cultural awareness to improve the quality of indigene-settler's interaction, relationship, and collaboration. Cultural awareness will produce two most important effects such as (a) change in attitudes that help indigenesettler feel cared for, accepted unconditionally, and respected for their individuality and contribution to the university; (b) reduced detachment of university management and a more involved, people-centred, and openness to addressing indigene-settler problems. Cultural awareness can be enabled by organising seminars and workshops and continuing professional development programmes to increase cultural knowledge, skills, and attitude. Finally, the emotional and psychological draining experienced within the university should be addressed by creating a psychologically fit work environment. The experienced emotional and psychological drain could influence work attitude, teamwork, and relationship vital for teaching, research, and community engagement. Thus, the experienced drain could disrupt the quality of services provided and subsequently the level of productivity in the university. The impact of services and productivity is the result of changes in lecturers' character, working memory, and pattern of communication with colleagues. This implies there is a need for university management to initiate and implement emotional adaptability programmes for lecturers.

3.2. Limitation of the Study. The study used three selected categories of Nigerian universities from two of the six geopolitical zones in Nigeria. This implies that the present sample is not a true representative of all Nigerian universities or zones.

\section{Conclusion}

The present study examined ethnic marginalisation and indigene-settler problems. Indigenes justified economic empowerment, food sources, and revival of cultural life and practices in addition to previous experience as a settler as motivations for ethnic marginalisation. Settlers identified resource control, domination, and power as reasons for some indigenes engaging in ethnic marginalisation. Both indigenes and settlers experienced emotional effects resulting from ethnic marginalisation as previous settlers, present indigenes, or present settlers. Furthermore, indigenes displaying discrimination and marginalisation and settlers demonising and calling the cultural practices of another ethnic group a fetish were not reported. The identified unreported cases provided the university management limited opportunity to address ethnic marginalisation and indigene-settler problems, which made the assumptions of some participants on the role that university management plays unverifiable. Although the present study did not identify the erupting indigene-settler problems that were common in the communities, the study recognised despair and anger in the narrative of both the indigenes and the settlers. The study also recognised that indigene-settler problems are shifting academic migration towards indigenous root, although an interesting finding but academic migration undermines contribution of diversity to quality in education. The present study suggests early intervention to curb the subtlety of ethnic marginalisation. 


\section{Data Availability}

The data used to support the findings of this study are available from the corresponding author upon request.

\section{Conflicts of Interest}

The author declares that there are no conflicts of interest.

\section{References}

[1] T. Shibutani and K. M. Kwan, Ethnic Stratification: A Comparative Approach, Macmillan, New York, NY, 1965.

[2] M. Weber, "Basic sociological terms," in Economy and Society, University of California Press, Berkeley, CA, USA, 1968.

[3] J. E. Trimble and D. Ryan, "Ethnic Identity," in Encyclopaedia of Applied Developmental Science, C. B. Fisher and R. M. Lerner, Eds., SAGE, Thousand Oaks, CA, USA, 2005.

[4] E. E. Osaghae, Crippled Giant: Nigeria since Independence, Hurst \& Company, London, UK, 1998.

[5] K. Allan, "Nation, Tribalism and National Language: Nigeria's Case (Nation, Tribalisme et Langue Nationale: le Cas du Nigeria)," Cahiers D'études Africaines, vol. 34, pp. 397-415, 1978.

[6] E. Ifidon, "Transitions from democracy in Nigeria: toward a pre-emptive analysis," African Journal of Political Science, vol. 7, no. 1, pp. 109-128, 2003.

[7] C. Anyanwu, "Critical reflection on values in Nigerian literature: pathways for Igbo society," Journal of Pan African Studies, vol. 11, no. 4, pp. 139-166, 2018.

[8] H. Tajfel, M. G. Billig, R. P. Bundy, and C. Flament, "Social categorization and intergroup behaviour," European Journal of Social Psychology, vol. 1, no. 2, pp. 149-178, 1971.

[9] E. Aronson, T. D. Wilson, and R. M. Akert, Social Psychology, Pearson Education, Upper Saddle River, NJ, USA, 2007.

[10] C. Achebe, "English and the african writer," Transition, vol. 75, pp. 342-349, 1997.

[11] Egbokhare and O. Francis, Leadership selection racket and tribalism in the contemporary Nigerian university system (Part I), 2016

[12] O. Nnoli, Ethnic Politics in Nigeria, Pan African Centre for Research on Peace and Conflict Resolution (PACREP), Enugu, Nigeria, 2008.

[13] M. B. Brewer, "The psychology of prejudice: ingroup love and outgroup hate?" Journal of Social Issues, vol. 55, no. 3, pp. 429-444, 1999.

[14] M.. Hewstone, M. Rubin, and H. Willis, "Intergroup bias," Annual Review of Psychology, vol. 53, no. 1, pp. 575-604, 2002.

[15] J. Zhang, "Conceptualizing a strain theory of suicide," Chinese Mental Health Journal, vol. 19, no. 11, p. 774, 2005.

[16] S. Jamshed, "Qualitative research method-interviewing and observation," Journal of Basic and Clinical Pharmacy, vol. 5, no. 4, pp. 87-88, 2014.

[17] Nigeria Research Network, Indigeneity, Belonging, and Religious Freedom in Nigeria: Citizens' Views from the Street, Nigeria Research Network, London, UK, 2014.

[18] N. Kyernum and A. S. Agba, "The indigene-ship question and its implication on the socio-economic development of Nigeria," Journal of Social Sciences and Public Policy, vol. 5, no. 2, 2013.

[19] A. Sayne, Rethinking Nigeria's Indigene-Settler Conflicts, US Institute of Peace, Washington, DC, USA, 2012.

[20] A. Adeyanju, "Symbols and not manifestos are the selling point here: a multimodal critical discourse analysis of two contemporary Nigerian political parties' images and slogans," in Political Discourse in Emergent, Fragile, and Failed Democracies, D. O. Orwenjo, O. Oketch, and A. H. Tunde, Eds., IGI Global, Hershey, PA, USA, 2016.

[21] E. J. Nwagwu, "Indigenes and settlers conflict in Nigeria: a negation to national integration and nation building," Mediterranean Journal of Social Sciences, vol. 4, p. 218, 2016.

[22] R. Gulati, “Tent Poles, tribalism, and boundary spanning: the rigor-relevance debate in management research," Academy of Management Journal, vol. 50, no. 4, pp. 775-782, 2007.

[23] G. Ehusani, Citizenship and the indigene/settler syndrome, 2005.

[24] W. Kigotho, AFRICA: Corruption is Eroding Higher Education's Benefits, University World News, London, UK, 2013.

[25] G. Nganga, Kenya: University Managers to be Reshuffled to Thwart Tribalism, University World News, London, UK, 2012.

[26] R. Bello, Our destructive obsession with tribalism, 2016.

[27] S. Crengle, E. Robinson, S. Ameratunga, T. Clark, and D. Raphael, "Ethnic discrimination prevalence and associations with health outcomes: data from a nationally representative cross-sectional survey of secondary school students in New Zealand," BMC Public Health, vol. 12, no. 1, p. 45, 2012.

[28] D. R. Williams and R. Williams-Morris, "Racism and mental health: the african American experience," Ethnicity and Health, vol. 5, no. 3/4, pp. 243-368, 2000.

[29] M. L. Greene, N. Way, and P. Kerstin, "Trajectories of perceived adult and peer discrimination among black, latino, and asian American adolescents: patterns and psychological correlates," Developmental Psychology, vol. 42, no. 2, pp. 218-236, 2006.

[30] R. Harris, M. Tobias, M. Jeffreys, K. Waldegrave, S. Karlsen, and N. James, "Effects of self-reported racial discrimination and deprivation on māori health and inequalities in New Zealand: a cross-sectional study," The Lancet, vol. 367, no. 9527, pp. 2005-2009, 2006.

[31] S. Karlsen and J. Y. Nazroo, "Relation between racial discrimination, social class, and health among ethnic minority groups," American Journal of Public Health, vol. 92, no. 4, pp. 624-631, 2002.

[32] N. Krieger, "Embodying inequality: a review of concepts, measures, and methods for studying health consequences of discrimination," International Journal of Health Services, vol. 29, no. 2, pp. 295-352, 1999.

[33] V. M. Mays, S. D. Cochran, and N. W. Barnes, "Race, racebased discrimination, and health outcomes among african Americans," Annual Review of Psychology, vol. 58, pp. 201225, 2007.

[34] N. Priest, P. Yin, P. Stewart, and J. Luke, "Racism and health among urban aboriginal young people," BMC Public Health, vol. 11, no. 1, p. 568, 2011.

[35] J. Stuber, S. Galea, J. Ahern, B. Shannon, and C. Fuller, "The association between multiple domains of discrimination and self-assessed health: a multilevel analysis of latinos and blacks in four low-income New York city neighborhoods," Health Services Research, vol. 38, no. 6p2, pp. 1735-1760, 2003.

[36] D. R. Williams and S. A. Mohammed, "Discrimination and racial disparities in health: evidence and needed research," Journal of Behavioral Medicine, vol. 32, no. 1, pp. 20-47, 2009.

[37] T. T. Lewis, C. D. Cogburn, and D. R. Williams, "Self-reported experiences of discrimination and health: scientific advances, ongoing controversies, and emerging issues," Annual Review of Clinical Psychology, vol. 11, pp. 407-440, 2015. 
[38] N. Priest, P. Yin, B. Trenerry, M. Truong, S. Karlsen, and Y. Kelly, "A systematic review of studies examining the relationship between reported racism and health and wellbeing for children and young people," Social Science \& Medicine, vol. 95, pp. 115-127, 2013.

[39] M. Sherif, "A study of some social factors in perception," Archives of Psychology, vol. 27, no. 187, 1935.

[40] E. A. Pascoe and L. Smart Richman, "Perceived discrimination and health: a meta-analytic review," Psychological Bulletin, vol. 135, no. 4, pp. 531-554, 2009.

[41] P. Ikejiani, "Education and tribalism," in Education in NigeriaSAGE, New York, NY, USA, 1965.

[42] L. Sun and J. Zhang, "Psychological strains and suicidal intent: an empirical study to relate the two psychopathological variables," Journal of Nervous and Mental Disease, vol. 204, no. 11, pp. 855-860, 2016.

[43] L. Comas-Diáz and F. M. Jacobsen, "Ethnocultural allodynia," The Journal of Psychotherapy Practice and Research, vol. 10, no. 4, p. 246, 2001.

[44] S. Okazaki, "Impact of racism on ethnic minority mental health," Perspectives on Psychological Science, vol. 4, no. 1, pp. 103-107, 2009.

[45] R. E. Park, Race and Culture, Free Press, Glencoe, IL, USA, 1964.

[46] R. E. Park, An Outline of the Principles of Sociology, Barnes \& Noble, New York, NY, USA, 1939.

[47] S. Grosby, "Debate: the verdict of history: the inexpungeable tie of primordiality-a response to eller and coughlan," Ethnic and Racial Studies, vol. 17, no. 1, pp. 164-171, 1994.

[48] M. K. Lapinski and R. N. Rimal, "An explication of social norms," Communication Theory, vol. 15, no. 2, pp. 127-134, 2005.

[49] K. Deaux and M. Verkuyten, "The social psychology of multiculturalism: identity and intergroup relations," in The Oxford Handbook of Multicultural Identity, Oxford University Press, New York, NY, USA, 2014.

[50] De Voss, S. Anna, S. Herman, C. B. Fouché, and C. S. Delport, Research at Grass Root for the Social Science and Human Service Professions, Van Schaik Publishers, Pretoria, NJ, USA, 2011.

[51] J. Sutton and Z. Austin, "Qualitative research: data collection, analysis and management," Canadian Journal of Hospital Pharmacy, vol. 68, no. 3, pp. 226-231, 2015.

[52] K. Maree, First Steps in Research, Van Schaik Publishers, Pretoria, NJ, USA, 2007.

[53] M. Walsh, Research made real: a guide for students, 2001.

[54] S. Kaur Johl and S. Renganathan, "Strategies for gaining access to doing fieldwork: a reflection of two researchers," Electronic Journal of Business Research Methods, vol. 8, no. 1, pp. 42-50, 2010.

[55] L. M. Given, The SAGE Encyclopaedia of Qualitative Research Methods: Volumes 1 \& 2, SAGE, Newbury Park, CA, USA, 2008.

[56] J. W. Creswell, Qualitative Inquiry and Research Design: Choosing Among Five Traditions, SAGE, Thousand Oaks, CA, USA, 1998.

[57] S. Herkama and A. Anne Laajalahti, Perspectives on softwareassisted qualitative data analysis: a systematic literature review, 2015.

[58] R. Elliott, C. T. Fischer, and D. L. Rennie, "Evolving guidelines for publication of qualitative research studies in psychology and related fields," British Journal of Clinical Psychology, vol. 38, no. 3, pp. 215-229, 1999.
[59] A. Bryman, Social Research Methods 4, Oxford University Press, New York, NY, USA, 2012.

[60] A. O. Muzan, "Insurgency in Nigeria: addressing the causes as part of the solution," African Human Rights Law Journal, vol. 14, no. 1, pp. 217-243, 2014.

[61] O. Lonsdale, "World catalogue of the family tanypezidae (Diptera: schizophora)," Zootaxa, vol. 3857, no. 3, pp. 412422, 2014.

[62] G. Diesendruck, R. Goldfein-Elbaz, M. Rhodes, S. Gelman, and N. Neumark, "Cross-Cultural differences in children's beliefs about the objectivity of social categories," Child Development, vol. 84, no. 6, pp. 1906-1917, 2013.

[63] O. Alubo, "Understanding the issues in the citizenshipindigenship crisis in Nigeria," in Dialogue on Citizenship in Nigeria, J. Golwa and O. Ojiji, Eds., Institute for Peace and Conflict Resolution, Abuja, Nigeria, 2008.

[64] P. A. Goff, C. M. Steele, and P. G. Davies, "The space between us: stereotype threat and distance in interracial contexts," Journal of Personality and Social Psychology, vol. 94, no. 1, p. 91, 2008.

[65] K. Kawakami, C. E. Phills, J. R. Steele, and J. F. Dovidio, "(Close) distance makes the heart grow fonder: improving implicit racial attitudes and interracial interactions through approach behaviors," Journal of Personality and Social Psychology, vol. 92, no. 6, pp. 957-971, 2007.

[66] J. J. Gross and O. P. John, "Individual differences in two emotion regulation processes: implications for affect, relationships, and well-being," Journal of Personality and Social Psychology, vol. 85, no. 2, pp. 348-362, 2003.

[67] J. J. Gross and R. W. Levenson, "Hiding feelings: the acute effects of inhibiting negative and positive emotion," Journal of Abnormal Psychology, vol. 106, no. 1, pp. 95-103, 1997.

[68] M. T. Feldner, M. J. Zvolensky, G. H. Eifert, and A. P. Spira, "Emotional avoidance: an experimental test of individual differences and response suppression using a biological challenge," Behaviour Research and Therapy, vol. 41, no. 4, pp. 403-411, 2003.

[69] S. C. Hayes, S. Kirk, K. G. Wilson, D. Toarmino, M. A. Polusny et al., "Measuring experiential avoidance: a preliminary test of a working model," The Psychological Record, vol. 54, no. 4, pp. 553-579, 2004.

[70] J. T. Levitt, T. A. Brown, and D. H. Barlow, "The effects of acceptance versus suppression of emotion on subjective and psychophysiological response to carbon dioxide challenge in patients with panic disorder," Behavior Therapy, vol. 35, no. 4, pp. 747-766, 2004.

[71] M. Mulinge, Tribalism in Universities: Who Will Stop it?. Capital Campus, 2013. 